\title{
X-linked endothelial corneal dystrophy
}

INSERM

\section{Source}

INSERM. (1999). Orphanet: an online rare disease and orphan drug data base. $\underline{X \text {-linked }}$ endothelial corneal dystrophy. ORPHA:293621

X-linked endothelial corneal dystrophy (XECD) is a rare subtype of posterior corneal dystrophy (see this term) characterized by congenital ground glass corneal clouding or a diffuse corneal haze, and blurred vision in male patients. 